\title{
Crónicas desde París: modernidad y capitalismo en César Vallejo
}

\author{
Marta ORTIZ CANSECO \\ Universidad Internacional de La Rioja
}

\begin{abstract}
RESUMEN
César Vallejo constituye una figura paradigmática como cronista en el contexto de la historia del periodismo peruano. Procedente de un país periférico, vivió en París (capital cultural europea a comienzos del siglo XX) casi la mitad de su vida, enviando artículos periodísticos a Perú como uno de sus pocos modos de subsistencia. En este texto estudiaremos el concepto de modernidad desarrollado por Vallejo en sus artículos y crónicas, así como el modo en que dicho concepto se relaciona con la sociedad capitalista parisina. La velocidad, la moda, el deporte, el cine y muchos otros aspectos de la ciudad de París le permitieron reflexionar sobre cuáles son los tiempos y los espacios en los que se mueve el hombre moderno, y de qué manera uno puede o no puede escapar a esas coordenadas que impone el capitalismo. Una lectura detallada de los textos periodísticos nos permitirá ver cómo Vallejo desarrolló una concepción original y propia de la modernidad, siempre en diálogo con intelectuales peruanos y latinoamericanos.
\end{abstract}

Palabras clave: César Vallejo, modernidad, crónicas, espacio, tiempo, cine, París.

\section{Chronicles from Paris: modernity and capitalism in Cesar Vallejo}

\begin{abstract}
César Vallejo, as a journalist, represents a paradigmatic figure in the context of Peruvian journalistic history. Vallejo lived most of his adult life in Paris (the European cultural capital in the first decades of the twentieth century) sending articles to Peru as one of his few ways of subsistence. In these pages we will study the concept of modernity Vallejo developed in his articles and chronicles, and also the way in which this concept links with Parisian capitalistic society. Speed, fashion, sports, cinema and many other aspects of the city led Vallejo to think about the times and spaces in which the modern human moves, and to imagine the possibility of subverting or avoiding the coordinates that capitalism enforces. A close reading of these texts will allow us to see how aspects of the modern city shape his thoughts and can be useful for a different reading of his poetry.
\end{abstract}

Key words: César Vallejo, Modernity, Chronicles, Space, Time, Cinema, Paris.

César Vallejo llega a París en julio de 1923. Lleva consigo la corresponsalía del diario trujillano El Norte, dirigido por su amigo Antenor Orrego, cuyo primer 
número había aparecido en febrero del mismo año y donde colaboraban otros componentes del Grupo Norte (también conocido como la Bohemia de Trujillo) y amigos de Vallejo como Alcides Spelucín, Federico Esquerre o Francisco Xandóval. Según Jorge Puccinelli, El Norte tuvo siempre buena acogida entre el público 'por su contenido de opinión, inusual en medio de la rutina del periodismo de la época, y se distinguió por sus editoriales valientes'; ofrecía información tanto nacional e internacional como regional, y se constituyó como un lugar abierto e integrador de los escritores jóvenes del Perú. Además de su colaboración para El Norte de Trujillo (1923-1930), a partir de 1925 — año en que consigue un puesto en la oficina de Les grands Journeaux Iberoaméricainnes, organización publicitaria dirigida por Alejandro Sux en París-, Vallejo comenzó a enviar regularmente artículos periodísticos a la revista limeña Mundial (entre 1925 y 1930) y más adelante a Variedades (entre 1926 y 1930) y al diario El Comercio (entre 1929 y 1930). Algunas de sus crónicas aparecían puntualmente en otras publicaciones periódicas como Amauta, e incluso en revistas latinoamericanas como Nosotros, de Buenos Aires, o Letras, de Santiago de Chile. ${ }^{1}$ Estas colaboraciones constituyeron la fuente principal de sus ingresos, y en cualquier vistazo mínimo que echemos a su epistolario veremos la insistencia con que continuamente reclamaba la retribución económica por sus envíos.

A finales del siglo XIX, el periodismo de opinión en el Perú se había ido transformando en un género más tendente a la información, más neutral; este proceso tuvo que ver con la evolución del campo económico pues, como señala Fernanda Beigel, de la supervivencia por suscripciones se fue pasando a la financiación por la publicidad. Más tarde, a comienzos del siglo XX, la prensa peruana va transformándose y van apareciendo los periódicos de alto tiraje. Con la primera Guerra Mundial el periodismo peruano vive su auge, entre 1915 y 1916, pero al finalizar la guerra Perú sufrió un gran cambio social 'que marcó la historia de la prensa con la explosión de las huelgas obreras y estudiantiles, que encontraron eco en algunos periodistas e intelectuales que adhirieron al movimiento'. También proliferó la prensa especializada, y surgieron las "revistas sociales", de lectura "obligatoria" para los emergentes sectores medios', que desarrollaron la crítica política mediante la ilustración y la caricatura, incluyendo diversos acontecimientos culturales, sociales e incluso deportivos. Ejemplo exacto de este tipo de

${ }^{1}$ César Vallejo, Artículos y crónicas completos, ed. Jorge Puccinelli, 2 vols. (Lima: PUCP, 2002), t. I, p. XXVII. El estudio preparado por Puccinelli para la edición de las crónicas resulta muy revelador, pues ofrece una hemerografía exhaustiva sobre los artículos y crónicas que se conocen de Vallejo y su lugar de publicación. Por ejemplo, Puccinelli señala que el peruano colaboró con las revistas francesas L'Amérique Latine, L'Europe Nouvelle, La Vie Latine, la española Sirio (Albacete) o la colombiana Cromos (I, XLVI). 
publicaciones en Perú lo constituyen revistas como Variedades (1908-1930) o Mundial (1920-1933), donde eran columnistas habituales autores como José Carlos Mariátegui o Vallejo; se trataba de un tipo de 'prensa no diaria que acompañó el creciente dinamismo del campo intelectual y el ascenso de nuevos sectores sociales'. ${ }^{2}$ Durante esos años muchos de los autores emergentes conciben el periodismo como un género ideal de entrenamiento intelectual, un lugar idóneo para que el artista desarrolle sus facultades críticas, que no cabían en otro espacio. Sin mencionar, por supuesto, que el ejercicio periodístico constituía una de las pocas posibilidades que el intelectual tenía de ganarse la vida.

En los primeros artículos que Vallejo envía a Lima desde París, sobre todo los dirigidos a El Norte, se percibe ese tono impresionista, ligero y frívolo que el modernismo había puesto de moda en las crónicas periodísticas. Como nota Jorge Puccinelli, en estos textos más juveniles y de impronta modernista se distingue un cierto regusto por la palabra rara, exquisita, refinada; un lenguaje generacional dirigido seguramente a sus compañeros de Trujillo, destinatarios principales de sus crónicas. Sin embargo, según avanzan los años, el discurso de Vallejo irá adquiriendo un tono muy personal que no encontramos en los primeros textos. Si al comienzo no parecía dispuesto a enemistarse con nadie (prueba de ello son las entrevistas que realiza a intelectuales ideológicamente opuestos a su pensamiento, como Francisco García Calderón), poco a poco vamos observando cómo desarrolla ese tono irónico tan característico de sus textos y se va tornando más crítico con la realidad socio-cultural que le rodea. En una misma crónica se suelen tratar varios temas, entre los que casi nunca falta el juicio crítico hacia uno $u$ otro aspecto de la frívola sociedad parisina. El estilo y las opiniones de Vallejo se van afilando a partir de 1925, año en que se inaugura su corresponsalía para la revista Mundial, dirigida por Andrés Avelino Aramburú, y cuando comienza a enviar crónicas más extensas y a trabajar en Les grands Journaux Iberoaméricainnes. Como señala Jorge Puccinelli, la colaboración con Mundial y con otras revistas españolas y latinoamericanas enfrentarán a Vallejo a un público más amplio e internacional que el público familiar al que se dirigía en El Norte. Este cambio, como decimos, se percibe en su tono y en su agudeza crítica sobre todo a partir de 1925, como si tomase conciencia de su posible representación en los sectores sociales emergentes de Latinoamérica.

Este proceso también tiene que ver con la situación personal de Vallejo. Recién llegado a París pasó varios meses de penurias económicas, e incluso tuvo que someterse a una operación quirúrgica, hasta que fue entrando en ciertas esferas culturales y rodeándose de algunos artistas que se convertirían más tarde en sus

${ }^{2}$ Fernanda Beigel, La epopeya de una generación y una revista. Las redes editoriales de José Carlos Mariátegui en América Latina (Buenos Aires: Biblos, 2006), p. 50. 
amigos. En 1924 conoció a Juan Gris y a Vicente Huidobro, en cuya casa entabla relación con Juan Larrea, y finalmente consigue el trabajo en Les grands Journaux. La miseria económica va aligerándose, y en 1926 publica junto con Larrea los únicos dos números de su revista Favorables París Poema, donde reúnen textos de Tzara, Reverdy, Diego, Huidobro, Gris, Neruda, etc. En 1925 Vallejo viajó por primera vez a España, para cobrar una beca conseguida gracias a la ayuda de su amigo Pablo Abril de Vivero, y va consiguiendo poco a poco hacerse un hueco en ciertas esferas intelectuales. Las crónicas que continuamente envía a Perú indican que el poeta asistía en primera fila, a veces a su pesar, a la aparición y desarrollo de las diversas corrientes culturales de París. Como señala Coyné, Vallejo no se limitó a ser testigo del mundo artístico que lo rodeaba, sino que quiso juzgarlo y muchas veces oponerse a él:

A partir de los hechos literarios, el cronista encara el problema del ser latinoamericano o, en un sentido a la vez más amplio y más restricto, indoiberoamericano. Se refiere a los debates entre intelectuales de credos más diversos, que desean sacar a sus respectivos países del estado de 'sociedades coloniales' en que perviven. ${ }^{3}$

Vallejo se relaciona con un grupo de escritores peruanos que contribuyeron al desarrollo de un nuevo tipo de ensayo, intelectuales como Emilio Romero, Luis E. Valcárcel, Jorge Basadre o Luis Alberto Sánchez. Según Flores Galindo, el periodismo de estos años, caracterizado por un afán polémico y renovador, consigue reformular la estructura de los libros; el ejemplo más nítido lo tenemos en los 7 ensayos de interpretación de la realidad peruana (1928) de José Carlos Mariátegui. Pero también Vallejo es autor de recopilaciones de reportajes periodísticos como Rusia en 1931 y Rusia ante el Segundo Plan Quinquenal, y otras obras fragmentarias pero de estilo más ensayístico como El arte y la revolución o Contra el secreto profesional. El ensayo constituye, para muchos autores de vanguardia, el género ideal para superar el desajuste entre afirmaciones orgánicas y fragmentarias; al utilizar los procesos de asociación y ensamblado se crea una 'estética de la discontinuidad' muy apropiada para traducir las preocupaciones de la época. Y lo que es más revelador, la predilección por el ensayo tiene que ver con 'la búsqueda de una comprensión global de los fenómenos, el afán por romper con especialidades estériles y buscar articulaciones entre la política y la economía, entre la cultura y la sociedad, entre el pasado y el presente'. ${ }^{4}$ Al mismo tiempo, el ensayo periodístico,

${ }^{3}$ André Coyné, Medio siglo con Vallejo (Lima: PUCP, 1999), p. 213.

${ }^{4}$ Alberto Flores Galindo, 'Los intelectuales y el problema nacional', Emilio Romero et al., 7 ensayos: 50 años en la historia (Lima: Empresa Editora Amauta, 1981), 139-156 (p. 146). 
en tanto género fragmentario, permite a los autores vanguardistas ofrecer una versión más fiel del momento que están viviendo y constituye una de las vías más eficaces de autonomización del campo cultural latinoamericano, pues el periodismo contribuyó a la legitimación de la formación de un discurso literario.

Vallejo enviaba crónicas a su país como una manera de ganarse la vida y cultivó los géneros periodístico y ensayístico de la misma manera que sus contemporáneos, con lo que se afirma la necesidad de analizar dichos géneros 'en su contemporaneidad, en el diálogo, el intercambio y la interpenetración de discursos ${ }^{5}$. No hay que leer estos textos, o el hecho de que existan, según nuestra manera de entender el ensayo o el periodismo hoy en día, sino que debemos tener en cuenta la actitud polifacética de tantos autores vanguardistas y entender que esa actitud responde a una formación determinada del campo cultural en la sociedad. A continuación trataremos de esbozar, mediante la lectura de los textos periodísticos de César Vallejo, los conflictos y problemas de la modernidad a los que se enfrenta un intelectual provinciano del Perú dentro de la esfera cultural hegemónica, la europea. Nelly Richard ha afirmado que ni la modernidad ni la posmodernidad deben ser leídas como etapas finitas en una lógica temporal o histórica, sino como nuevas lecturas y revisiones de los conceptos en crisis sobre la razón universal. ${ }^{6}$ No debemos preguntarnos cuándo o por qué comienza la modernidad, sino qué tipo de revisiones surgen respecto a los conceptos heredados. En este sentido, los textos de César Vallejo pueden considerarse paradigmáticos, pues su autor vive en el centro del pensamiento hegemónico (París) y sin embargo procede de la periferia; de manera que no solo revisa los conceptos dominantes, sino que resignifica, al ocuparlo, el lugar en el que se encuentra, porque atraviesa e incide en las estructuras culturales hegemónicas desde una perspectiva externa.

Cabe destacar que el grueso de la producción periodística del poeta se ubica en la década del veinte, ya que el compromiso social que adquiere en los años treinta probablemente no gustaba a los editores de El Comercio, Mundial y Variedades por

${ }^{5}$ Celina Manzoni, 'Formas de lo nuevo en el ensayo de la vanguardia: revista de avance y Amauta', Revista Iberoamericana, LXX:208-209 (2004), 735-747 (p. 739). Además, Manzoni alude a una frase del prólogo de Mariátegui a su primer libro La escena contemporánea (1925), que resulta muy apropiada en este contexto: 'el mejor método para explicar y traducir nuestro tiempo es, tal vez, un método un poco periodístico y un poco cinematográfico' (p. 741). El concepto de 'estética de la discontinuidad', antes mencionado, también pertenece a este artículo. Más adelante veremos cómo se mezcla, en Vallejo, el discurso periodístico con el lenguaje cinematográfico.

${ }^{6}$ Nelly Richard, 'Alteridad y descentramiento culturales', Revista Chilena de Literatura, 42 (1993), 209-215 (p. 210). 
su 'exaltación del comunismo', según señalan Fernández y Gianuzzi. ${ }^{7}$ Sin embargo, las alusiones del poeta a las rápidas transformaciones de la ciudad moderna, a sus engaños y a sus defectos, aparecen en casi todos sus textos. Existe una crónica en la que Vallejo desacraliza la idea de París como ciudad única, expresando el desengaño definitivo de los latinoamericanos, que 'han progresado mucho y ya no se dejan embaucar por este París que literatos culpables o ramplones han prestigiado de leyendas mágicas'. La capital francesa se presenta como una ciudad común y corriente, igual a todas las ciudades, y en ella no se encuentra más que lo que puede encontrarse en cualquier ciudad del mundo. Lo que pretende el autor peruano es echar por tierra los prejuicios de sus compatriotas, que llegan a París pensando encontrar maravillas inverosímiles:

Todo en París está dentro de lo previsto por la lógica y la razón o dentro de lo que ya se ha visto en las otras ciudades. Nada en París se sale de lo normal. Los transeúntes andan en dos pies, como en todas partes; la lluvia cae, como en todas partes, del cielo. [...]

El sudamericano, al embarcarse en Valparaíso o en Veracruz, se prometía ver en París cosas maravillosas, fenomenales, cosas auténticas y típicamente "parisienses": un hombre con tres espaldas; una piedra que habla; una bailarina epicena; un círculo cuadrado; en fin, el movimiento continuo...

Entonces, el provinciano que llega a París sufre un desengaño porque su imaginario socio-cultural está colonizado por la idea de un París cósmico y todopoderoso; pero al llegar todo resulta normal, incluso familiar. En este texto se une la desacralización de la capital francesa con varias ideas que desarrollaremos a continuación. En primer lugar existe la mofa ante la idea de ver cosas auténticas, como si el traslado a la capital supusiese un salir al mundo, una experiencia de la vida auténtica, real. Vallejo boicotea la manera de razonar, de percibir 'la realidad', que se ofrece como la única válida para el mundo occidental. En segundo lugar, encontramos en el texto la referencia a esa especie de movimiento continuo, que tiene que ver con el mito de la velocidad, otro concepto clave de la percepción de la modernidad en Vallejo. Por último, se juega con la idea de un espacio donde todo es predecible, porque nuestro punto de partida (nuestro único contexto) es la razón (el razonamiento) del ser humano occidental. O planteado de otra manera: nuestras expectativas nos imponen las posibilidades de experiencia que podemos adquirir.

${ }^{7}$ Carlos Fernández y Valentino Gianuzzi, César Vallejo en Madrid en 1931: itinerario documental (Madrid: El Centro Editores, 2012), s. p.

8 'Sociedades coloniales', Mundial, 410, 20 abril 1928 (II, 578-580). En adelante, las citas a las crónicas de Vallejo se harán de esta manera: los datos exactos de su publicación, seguidos del tomo y la página de la edición de Puccinelli, de donde se toman las citas. 
Más adelante insistiremos en esta idea, pero lo que importa ahora es que la ciudad soñada resulta ser una ciudad más, inserta en el mundo moderno y con las mismas opciones que cualquier otra urbe: no se nos ofrecen ni más ni menos posibilidades que las ya conocidas. Así, velocidad y espacio se imbrican en el imaginario vallejiano para ofrecernos las dos claves principales con las que leeremos su visión de la modernidad:

La velocidad es la seña del hombre moderno. Nadie puede llamarse moderno sino mostrándose rápido. [...] No hay que olvidar, por lo demás, que la velocidad es un fenómeno de tiempo y no de espacio; hay cosas que se mueven más o menos ligeras, sin cambiar de lugar. Aquí se trata del movimiento en general físico y psíquico. En algún verso de Trilce he dicho haberme sentado alguna vez a caminar. [...]

No hay que confundir la velocidad con la ligereza, tomada esta palabra en el sentido de banalidad. Esto es muy importante.

Dos personas contemplan un gran lienzo; la que más pronto se emociona, esa es la más moderna. ${ }^{9}$

Muchos de los aspectos que estamos analizando en estas páginas se encuentran ya, como señala Vallejo, en Trilce. Pero lo que nos interesa ahora son los juicios del poeta sobre la modernidad y el progreso, cómo afronta el desarrollo de las ciudades y del ser humano. En este caso la modernidad se define por la velocidad, que rige el ritmo de la vida y constituye al hombre moderno como tal. Pero no la velocidad del movimiento, no la rapidez en el espacio, como señalaban sus coetáneos vanguardistas, sino la velocidad en todos los ámbitos de la existencia: en las emociones, en la sensibilidad, en el tiempo. Vallejo entiende que el tiempo en movimiento constituye una de las bases de la modernidad; el hombre moderno nace dentro del tiempo, con su velocidad dada, sin conocer su origen, pero convencido de la veracidad del tiempo como rector de su universo. No se trata entonces de admirar la velocidad en el espacio (el espacio social del capitalismo avanzado), como hacían los futuristas, sino de cuestionar ese mismo espacio y de analizar la velocidad en el tiempo, la reflexión desde el reposo sobre una nueva concepción del tiempo: 'Pobre del hombre que, en medio de las rápidas transformaciones a que asistimos ahora, no excede o siquiera se nivela a la velocidad de los hechos'. El transcurso de los acontecimientos va superando al hombre, lo sobrepasa; la época misma se adueña de los hechos y quien no consigue comprenderlo debe excluirse 'consciente o inconscientemente, de la época. Apenas unos cuantos se adaptan al

\footnotetext{
9 'El hombre moderno', El Norte, 13 diciembre 1925 (I, 173-174).
} 
nuevo paso y lo dominan'. ${ }^{10}$ Para Vallejo, entonces, el tiempo rige el desarrollo de la modernidad.

Pero ¿en qué sentido estamos hablando del tiempo? No se trata solo de verlo como un leit motiv en sus textos, sino de entender que la modernidad trae al hombre una nueva concepción del tiempo, y detenernos en la manera singular, incluso cómica, en que nuestro poeta percibe este cambio: 'El reloj, antes enemigo acérrimo del artista, no falta ahora del pulso del poeta y del aviador. [...] Hasta el sueño está ahora ajustado, por la derecha, a la aguja del reloj y, por la izquierda, a la aguja de la brújula'. ${ }^{11}$ Aquí tenemos el reloj como sinónimo del tiempo y la brújula como sinónimo del espacio. En otra crónica alude al cambio de horario en el hemisferio norte y hace notar que el titular del periódico, donde se indicaba que 'esta noche, a las once serán las doce', recordaba a uno de sus versos de Trilce: 'Quién clama las once no son doce'. El poeta halla entonces la confirmación, paradójicamente seria, de aquello que otras veces afirmaba con humor: 'Son las once o, lo que es igual, las doce de la noche'. ${ }^{12}$ Vallejo parece insinuar, en toda su obra, que este tipo de afirmaciones solo son contradictorias en el lenguaje.

La velocidad del tiempo aparece como un síntoma de la modernidad capitalista y, en el mismo registro cómico, se suele llevar a cabo también un cuestionamiento del espacio de esa modernidad (entendido como algo mucho menos dinámico, e incluso menos moderno, que el tiempo). Un ejemplo claro podría constituirlo la siguiente afirmación: 'los lugares no siempre están situados donde los hemos visto, sino que ellos saben andar y burlarse de nuestros ojos'. La llamada de atención sobre nuestra manera de percibir el espacio encaja con la observación de que nuestros modos de intuición son 'tan antiguos como el mundo', y solo los hombres 'tienen la inclinación a ir sobre seguro, esto es, por las vías inmediatas de la realidad lógicamente practicable'; al contrario que los niños y los locos, quienes, según Vallejo, ponen en práctica métodos de creación y descubrimiento más arriesgados que los de los hombres. Es necesario burlar la pobre lógica del ser humano para luchar contra el engaño de nuestra percepción del espacio. 'Los lugares son terribles' porque 'suelen ambular en el espacio y en el tiempo y burlarse de los ojos del historiador o del simple mortal', de manera que para aprehenderlos 'no siempre

10 'La semana santa en París', Mundial, 414, 18 mayo 1928 (II, 593).

11 'Las nuevas disciplinas', Variedades, 1017, 27 agosto 1927 (I, 461).

${ }^{12}$ En palabras de Vallejo, 'hay versos en ese maldito Trilce que, justamente por derrengados y absurdos, hallan su realización cuando menos se espera. Son realizaciones imprevistas y cómicas, pero espontáneas y vitales. Aquello de que esta noche las once sean doce en París, no puede ser más cierto y viviente. El que pretende sustraerse a esta articulación - itsmo o canal — entre ambos números del reloj, tendrá que asumir todas las consecuencias de su rebeldía', en 'París en primavera', El Norte, 12 junio 1927 (I, 438-440). 
debe uno guiarse de la perspectiva inmediata y visible, sino [que] hay que saltar abismos inauditos, apelando consciente o subconscientemente a truculentas aventuras y a cábalas y odiseas absurdas'. ${ }^{13}$

En Las palabras y las cosas, Foucault afirmaba que el hombre moderno carece de origen, pues para él todo es historicidad; y no es el origen el que da lugar a la historicidad, sino que es dentro de esta donde se perfila la necesidad de un origen, que será a la vez interno y extraño. Como ya señaló Nietszche, la historicidad creada por el hombre se convierte en rectora de su existencia, haciéndole creer que depende de ella, y no al revés. ${ }^{14}$ El hombre se descubre ligado a una historicidad ya hecha; de la misma manera que nace en un lenguaje ya formado, un lenguaje que se le impone. Muchos de los textos de Vallejo muestran que comprendía muy bien este proceso, como cuando juega a boicotear los axiomas del hombre moderno: 'Podríamos quedarnos sin nacer pero no podríamos quedarnos sin morir'. ${ }^{15}$

Constituye otro lugar común en las crónicas de Vallejo el escaso interés que muestra por la modernidad entendida como progreso: 'Ya no hay campos ni mares en Europa; ya no hay templos ni hogares. El progreso mal entendido y peor digerido los ha aplastado. (...) Me han dicho que solo España y Rusia, entre todos los países europeos, conservan su pureza primitiva, la pureza de gesta de América'. La nostalgia por una pureza primitiva tiene que ver en este momento con el crecimiento desorbitado de la ciudad, que por primera vez podía ser presenciado en la corta duración de una vida humana, tal y como ha señalado Ángel Rama. ${ }^{16} \mathrm{Se}$ produce así un fuerte desarraigo del individuo dentro de su entorno, con el que deja de identificarse por su constante transmutación y disolución. Esta experiencia de desarraigo fue generalizada, pues la viven quienes residen en las ciudades y también aquellos que llegan de fuera. Aunque Rama se refiere a las ciudades latinoamericanas, los cambios que comenzaron en las metrópolis europeas a finales del siglo XIX se extendieron también a las primeras décadas del siglo XX. No debemos olvidar, además, que Vallejo procedía de un pequeño pueblo de la sierra peruana, con lo que su sensación de nostalgia, de inestabilidad y de extrañamiento podía verse duplicada. Esta situación nos lleva, de nuevo, a ese lugar de enunciación escindido que el poeta resignifica desde sus textos:

${ }^{13}$ Todas las citas del párrafo en 'Las pirámides de Egipto', Mundial, 302, 26 marzo 1926 (I, 205-207).

${ }^{14}$ Michel Foucault, Las palabras y las cosas. Una arqueología de las ciencias humanas (Madrid: Siglo XXI, 2006 [1. a ed. 1966]), p. 320. Friedrich Nietzsche, 'Sobre verdad y mentira en sentido extramoral', en Antología, eds. J. B. Llinares y G. A. Meléndez (Barcelona: Península, 2003), 65-82.

15 'La necesidad de morir', El Norte, 22 marzo 1926 (I, 203).

${ }^{16}$ Ángel Rama, La ciudad letrada (Santiago de Chile: Tajamar Editores, 2004 [1. ${ }^{a}$ ed. 1984]). 
Qué amable es perderse por falta de caminos. Ahora tengo ansia de perderme definitivamente, no ya en el mundo ni en la moral, sino en la vida y por obra de la naturaleza. Odio las calles y los senderos. Cuánto tiempo he pasado en París, sin el menor peligro de perderme. La ciudad es así. No es posible en ella la pérdida, que no la perdición, de un espíritu. En ella se está demasiado asistido de rutas ya abiertas, de fechas y señales ya dispuestas, para poder perderse. Al revés de lo que ocurrió a Wilde, la mañana que iba a morir en París, a mí me ocurre amanecer en la ciudad, siempre rodeado de todo, del peine, de la pastilla de jabón, de todo; estoy en el mundo con el mundo, en mí mismo conmigo mismo; llamo e inevitablemente me contestan y se oye mi llamada; salgo a la calle y hay calle; me echo a pensar y hay siempre pensamiento. ${ }^{17}$

Vallejo escribió este texto durante uno de sus primeros viajes a España, y la fobia al camino ya hecho no solo muestra la sensación de extrañamiento frente al avance de la modernidad en las ciudades, sino que puede resultar muy reveladora para comprender una parte de su práctica poética. Como señala José Ignacio Padilla, 'Vallejo vio muy claramente la conexión entre el vaciamiento del lenguaje y la disponibilidad de un "repertorio" de experiencia'. ${ }^{18}$ Dicho de otra manera: el autor de Trilce habla de la imposibilidad de perderse dentro de un mundo que ofrece distintos caminos ya formados, predispuestos, donde elegir uno u otro forma parte del juego mismo. La ciudad moderna ofrece, como el lenguaje, determinados modos de experiencia disponibles para todos, y elegir uno u otro modo no significa ser más o menos original, sino entrar en el juego previsto por la ciudad misma. Por eso resulta imposible perderse, y por eso 'si llamo es previsible que me contesten', de la misma manera que si salgo a la calle en la ciudad, inevitablemente habrá calle.

En algunas crónicas, el poeta se detiene ante este descubrimiento con un humor muy característico, como queriendo jugar con el lector. Por ejemplo en el texto 'El sombrero es el hombre', Vallejo trata de demostrar que el sombrero es anterior al hombre, marcando la diferencia entre el sombrero natural ('aquel que nace con cada persona y que le es inseparable') y el sombrero artificial ('aquel que se adquiere en sombrererías y del cual podemos separarnos momentánea o eternamente'). El tono irónico y juguetón del poeta por momentos descentra la atención del lector impidiéndole entender en toda su dimensión aquello que en realidad afirma:

${ }^{17}$ Esta cita y la anterior pertenecen a la crónica 'Entre Francia y España', Mundial, 290, 1 enero 1926 (I, 180-183). Mis reflexiones sobre la ciudad moderna europea se han visto también enriquecidas por el estudio de Carl E. Schorske, Viena Fin-de-Siècle. Política y cultura (Barcelona: Editorial Gustavo Gili S. A., 1981).

${ }^{18}$ José Ignacio Padilla, 'Eielson: De materia verbalis', Hueso Húmero, 54 (2009), 23-54 (p. 24). 
Todas las cosas llevan su sombrero. Todos los animales llevan su sombrero. Los vegetales llevan también el suyo. No hay en este mundo quien no lleve la cabeza cubierta. Aun, cuando nos quitamos el sombrero, siempre queda nuestra cabeza tocada de algo que podríamos llamar el sombrero innato, natural y tácito de cada persona, que no es del todo inseparable. [...]

Así, pues, el sombrero es el hombre o, más generalmente, el sombrero es todo. ${ }^{19}$

Como si siempre hubiese algo de lo que el ser humano no pudiese desprenderse, algo que le precede y que lo abarca todo. Volvemos a Foucault para explicar que lo que se comienza a entender en el s. XIX 'no es la soberanía de un discurso primero, es el hecho de que nosotros estamos, antes aun de la menor palabra nuestra, dominados y transidos ya por el lenguaje ${ }^{20}$ Todo está ahí cuando nacemos, se nos ofrece como un repertorio de posibles experiencias: tanto la ciudad como el lenguaje rodean al hombre moderno y perfilan sus necesidades. Por eso afirmábamos antes, con Nelly Richard, que el hombre moderno es incapaz de ver la modernidad como un proceso lineal y finito, con un punto de origen, porque pertenece a ella. La trampa será creer que se puede elegir un camino voluntariamente y no porque todos los caminos de la modernidad nos son impuestos. De esta manera entiende Vallejo la ciudad, la moda, la velocidad intrínseca a la vida moderna, y sobre todo así transmite también su concepción del lenguaje.

En la narración citada de su viaje a España ('Entre Francia y España'), Vallejo cuenta que por fin se siente libre de todo lo que la ciudad moderna supone: 'heme por fin libre de calles, de rieles, esquinas, telégrafos, torres, teatros, periódicos, escritores, hoteles, peine, jabón, de todo esto que, de una u otra manera, es camino; heme libre hasta de pensamientos'. Sin embargo, más adelante en el mismo texto, Vallejo afirmará de nuevo que incluso los campos de Europa no son más que sucursales de la ciudad, 'trozos de París, pingajos de Londres, postas de urbe', pues siempre habrá una máquina presente, un neumático, un reloj, el ruido. 'Los campos de Europa, los mares del viejo continente, son campos de salón, mares en smoking, urbanos, civilizados, policés'. Esta nostalgia por un tipo de arcadia americana perdida constituye también, no lo olvidemos, un modelo de experiencia vigente por lo menos desde el 'descubrimiento' de América.

La ironía constante de Vallejo ante el avance de la modernidad nos lleva al tema del deporte, o la deportividad como modo de vida. En una sociedad 'de récords y de colmos' el criterio que rige en todo, dice Vallejo, es el de la cantidad. Todas las actividades humanas son valoradas según la competitividad, la cantidad de esfuerzo y el resultado obtenido; lo que antes se veía como una batalla sangrienta es ahora un

19 'El sombrero es el hombre', Variedades, 964, 21 agosto 1926 (I, 275-276).

${ }^{20}$ Foucault, Las palabras..., p. 292. 
'match estupendo, plural, multifacético', donde todos se convierten en rivales. La competitividad deportiva aparece como la representación de los valores de una sociedad capitalista:

El mundo, conjuntamente con la moda del sport, va adoptando el sentimiento del récord para todas las actividades. [...] La vida, como match, es una desvitalización de la vida, como diría Antenor Orrego. Pulpa moral del match es la esclavitud y el amujeramiento. Yo no vivo comparándome a nadie ni para vencer a nadie y ni siquiera para sobrepujar a nadie. Yo vivo solidarizándome $\mathrm{y}$, a lo sumo, refiriéndome concéntricamente a los demás, pero no rivalizando con ellos. ${ }^{21}$

Para Vallejo, es la guerra mundial la que puso de moda el deporte como modo de competición entre naciones. El poder y la vitalidad de un pueblo se mide por sus recursos materiales pero también por su capacidad deportiva. Es interesante notar cómo el peruano relaciona el desarrollo de la moda deportiva con el creciente imperialismo norteamericano, afirmando que hay 'una racha mundial de imitación del deporte de origen u orientación yanqui'; dicha imitación trae consigo un conocimiento mayor de la sociedad norteamericana, por ejemplo cuando en el ciclismo se compite en 'equipos bipersonales, como conviene a la concepción colectivista o taylorista del yanqui'. La imbricación entre deporte y sociedad constituye otro de los aciertos de Vallejo en su observación sobre los síntomas de la modernidad. ${ }^{22}$

El enfrentamiento entre Europa (París) y Norteamérica (Nueva York) se produce también a modo de match. Aunque su lucha no se hace frente a frente sino de manera oblicua (según el espíritu burgués, dice Vallejo), pues si con la primera Guerra Mundial se había cerrado una época, los años veinte serán los que gesten la crisis de los treinta, que desembocará en la Guerra Civil española y luego en la segunda Guerra Mundial. Contradicciones y luchas entre socialismo moderno y fascismo, la loca carrera del desarrollo capitalista, las competiciones internacionales por convertirse en potencias económicas mundiales, etc., son factores que se encuentran en plena efervescencia en la época de entreguerras. Como hemos mencionado, el rostro negativo de la modernidad equivale, en Vallejo, a la angustia por la deshumanización del progreso. Así lo declara cuando afirma que en Madrid 'tales instrumentos de progreso no nos angustian, ni nos dan de trompicones, ni nos dominan, ni obstruyen el libre y desinteresado juego de nuestros instintos de señorío

21 'La vida como match', Variedades, 1021, 24 septiembre 1927 (I, 476-477).

22 'Los sprints ciclistas corresponden, en cuanto afirmación espectacular del espíritu yanqui, a los golpes de bolsa de Chicago o a las hazañas melodramáticas del Ku Klux Klan', en 'Los seis días de París', Mundial, 415, 25 mayo 1928 (II, 597-598). 
sobre las cosas; en una palabra, que no nos hacen desgraciados' ${ }^{23}$ Su contacto con la España pobre de la década del veinte constituirá un primer acercamiento a la posibilidad de un tipo de ciudad europea humanizada, que abrace e integre, pero no se someta a la alienación del progreso. Aunque Vallejo asistió a la proclamación de la segunda República española con escaso entusiasmo, desde su primer viaje a la península creyó ver en el pueblo hispánico cierta modernidad ideal, en lugar de esa 'tragedia de progreso' de la que habla a menudo.

La idea de la modernidad en Vallejo también gira en torno a la aparición y el desarrollo del cine como el elemento que más revolucionó el desarrollo del arte en esos años. Nuestro poeta dejó varios escritos referentes al séptimo arte, algunas reseñas sobre películas y lo que más nos interesa aquí: breves notas sobre lo que el cine significaba en una época de cambio en la sensibilidad artística. Para Vallejo no se trata de una mera reproducción de la realidad en movimiento, el cine no es una postal recreativa de un ambiente, como el teatro. Según Michelle Clayton, el cine sustituyó rápidamente el interés de Vallejo por el teatro, puesto que suponía un respiro de las formas lingüísticas tradicionales en favor de una sintaxis puramente visual. ${ }^{24}$ En varios momentos, Vallejo insiste en que el logro del cine no se puede reducir 'a un simple arte de mise en scène', donde el movimiento resuelve, con mayor verosimilitud que en el teatro, la distancia entre tiempo y lugar. La consistencia estética del cine no puede basarse solo en su reproducción de la realidad, sino que se trata de algo superior, un género que permite la creación de un nuevo arte; el cine constituye 'un nuevo resorte creador'. Así lo reivindica el peruano en una reseña sobre la película Napoleon (1927), de Abel Gance, que no resalta por su belleza sino por constituir 'un ensayo de rítmica a tres pantallas'. Efectivamente, la película se proyectó sobre tres pantallas conectadas, con tres temas diversos, mostrando al espectador una audacia más en la experimentación cinematográfica. El paisaje que se ofrece en las pantallas puede resultar vulgar, pero del ritmo que se produce con dicho efecto 'se pueden deducir muy densas

23 'Wilson y la vida ideal en la ciudad', Mundial, 295, 5 febrero 1926 (I, 185). Vallejo añade en el mismo texto: 'La energía física, el vigor químico, los voltios de luz, la pantalla cinematográfica, el correo del aire, el vencimiento bancario, todo se hace en Madrid comprensivo, inteligente, para arreglárselas satisfactoriamente con el hombre y siempre a favor de su dicha'.

${ }^{24}$ El texto de Vallejo al que pertenecen las citas que siguen es 'Ensayo de una rítmica a tres pantallas', Variedades, 1054, 12 mayo 1928 (II, 590-592). La cita exacta de Clayton es: 'Cinema quickly displaces Vallejo's interest in theatre, in large measure because it offered a sensorial respite from linguistic histrionics through its purely visual syntax'. Michelle Clayton, Poetry in pieces: César Vallejo and Lyric Modernity (California: University of California Press, 2011), p. 187. 
consideraciones relativas al movimiento como factor de la ubicuidad de las imágenes'.

Como mostraremos a continuación, existen varios puntos que permiten relacionar las intuiciones de Vallejo con las ideas desarrolladas pocos años después por Walter Benjamin. ${ }^{25}$ La discusión sobre si la fotografía constituía o no un nuevo arte muchas veces precedió a la tarea reflexiva de cómo su invención modificaba completamente el carácter mismo del arte. El cine, no hace falta decirlo, agravó las dificultades de clasificar estos nuevos procesos dentro de la estética tradicional; así, los críticos, empeñados en ensamblar el cine en el arte, utilizaban en sus interpretaciones todo tipo de elementos culturales tradicionales. Benjamin reivindica, sin embargo, una mirada atenta a lo que el cine cambió en las estructuras mismas del arte y de la percepción del ser humano. Y en esta línea reflexiva situamos a Vallejo cuando afirma que el cine no es simple reproducción de algo, sino que realmente supone un nuevo arte, un nuevo resorte creador. De ahí que se muestre reacio al cine hablado, pues este contribuye a que se teatralice la pantalla, 'descinematizándola en lo que ella tiene de privativo y original, como arte independiente del teatro'.${ }^{26}$ Una de las características propias del cine era el silencio, la imagen muda en la pantalla, que facilitaba la nueva percepción de las imágenes.

Si el psicoanálisis permitió la aprehensión del inconsciente pulsional, el cine, dice Benjamin, nos ayuda a experimentar el inconsciente óptico, porque con él profundizamos en posibilidades de percepción nunca antes desarrolladas, tanto en el mundo óptico como en el acústico. No es que el cine aclare de otra manera algo que no se veía claro, sino que pone de manifiesto formaciones estructurales del todo nuevas; porque 'la naturaleza que habla a la cámara no es la misma que la que habla a nuestros ojos. Es distinta, sobre todo, porque el espacio que el hombre dominaba con su consciencia es sustituido por otro en el que impera la inconsciencia'. ${ }^{27}$ Entonces, el cine muestra más cosas de las que parece mostrar. Algo de esto intuye Vallejo cuando enumera con asombro algunas escenas de Eisenstein en $E l$ acorazado Potemkin y La línea general:

${ }^{25}$ Walter Benjamin, La obra de arte en la época de su reproducción mecánica (Madrid: Casimiro Libros, 2010 [1. ${ }^{\mathrm{a}}$ ed. 1955, escrito en 1935]). Rafael Gutiérrez Girardot también ha estudiado los parecidos entre Vallejo y Benjamin, desde el punto de vista del marxismoleninismo, en su artículo 'César Vallejo y Walter Benjamin', Cuadernos hispanoamericanos, 520 (1993): 55-72.

26 'Un año teatral en Europa', Mundial, 431, 14 septiembre 1928 (II, 643).

${ }^{27}$ Benjamin, p. 47. Cabe la posibilidad de que Vallejo leyese alguno de los textos de Abel Gance sobre cine citados por Benjamin, como por ejemplo 'Le temps de l'image est venu', en L'art cinématographique, II, Paris, 1927. 
Por ejemplo: un friso de tractores, vistos desde un avión, enroscándose como una serpiente sobre el predio del kolkos; [...] el proceso de transformación de la leche en queso, mantequilla y demás productos derivados; la marea de un trigal, levantada por la brisa (placa negativa), y dorada — todo el cromo del oro- por el sol y las nubes (placa positiva). ${ }^{28}$

Lo que en principio supone una exaltación del marxismo, y del modo en que Eisenstein ensalza el trabajo como motor del hombre, puede leerse también como una reflexión sobre la manera en que el cine permite percibir escenas cotidianas y presentar ante el espectador la mano que ordeña y la máquina de ordeñar, como algo nunca antes percibido de esa forma por el ojo humano. Además, las imágenes, que se suceden con rapidez, desvelan en poco tiempo lo que en la naturaleza necesita de días y semanas, como el proceso de transformación de la leche en queso. Vallejo lo sabía: el cine ofrece nuevas maneras de mirar y tergiversa nuestra percepción del tiempo.

La difusión masiva de la obra cinematográfica constituye otra de las características señaladas por Benjamin. Es precisamente la reproductibilidad técnica de la obra artística lo que modifica la relación entre la masa y el arte, pues la pintura nunca había ofrecido una recepción simultánea y colectiva de la manera en que lo hizo el cine. Esa misma reproductibilidad causa la pérdida de la autenticidad o del aura de la obra, tal y como señala Benjamin, pues cuando una obra es reproducida lo que pierde por encima de todo es su autenticidad. Sin embargo, en autores como Vallejo, esta recepción colectiva es exaltada como un paso más para acercar el arte a las masas; la difusión masiva se ve como una posibilidad de socializar el arte. Además, según apunta Benjamin, la reproducción técnica de la obra cinematográfica no es una condición extrínseca de su difusión masiva (como en la pintura, por ejemplo), sino que nace en la misma técnica de su producción y esa difusión masiva le es impuesta para que sea rentable. Es por ello que el cine sonoro tuvo un primer momento de retroceso económico, puesto que limitaba al público por sus fronteras lingüísticas. Se explican así los reparos de Vallejo ante el cine hablado como nueva frontera idiomática, que en lugar de ofrecer un arte accesible a todas las naciones, las separaba según sus lenguas: 'El cinema hablado crea nuevas fronteras, separa a los pueblos. Es, desde este punto de vista, antisocialista, contrarrevolucionario'. No es casualidad, tampoco, que Benjamin note la coincidencia entre el momento de desarrollo del cine sonoro y la expansión de los

${ }^{28}$ El capítulo XIV de Rusia en 1931 está dedicado al cine ruso y se titula 'El cinema. Rusia inaugura una nueva era en la pantalla'; César Vallejo, Ensayos y reportajes completos, ed. Manuel Miguel de Priego (Lima: PUCP, 2002), p. 154-155. 
intereses nacionales del fascismo; ambos fenómenos fueron simultáneos y respondían al mismo acicate: el de la crisis económica. ${ }^{29}$

La última de las observaciones de Vallejo que nos interesa relacionar con la teoría de Benjamin es la que se refiere al actor. El cine soviético, además de otras técnicas revolucionarias, pone en práctica una verosimilitud sin precedentes cuando, en los momentos multitudinarios de las películas, no trabaja con 'actitudes y movimientos artificiales o voluntarios de actores, sino con actos y peripecias vitales de masas e individuos que no son actores, y que, al ser filmados, no hacían más que vivir la realidad auténtica y extracinemática de la vida cotidiana'. ${ }^{30}$ Vallejo lee esta novedad como otro de los puntos esenciales para acercar el arte a la vida, y conseguir que el arte sea la vida misma. Según Benjamin, el hecho de que en el cine soviético muchos actores desempeñasen su propio papel tenía que ver sobre todo con la nueva manera de percibir las estructuras del arte. En la literatura, por ejemplo, ocurrió durante siglos que a un escaso número de escritores se enfrentaba un número de lectores mucho mayor; en el siglo XIX esto comienza a cambiar, hasta el punto de que hoy en día cualquiera puede escribir y publicar algo en un momento dado de su vida; la distinción entre unos y otros deja entonces de ser sistemática. En el cine se logra este cambio en mucho menos tiempo, y no solo cualquiera puede pasar de ser espectador a convertirse en actor, sino que algunos actores pueden desempeñar su propio papel.

Lo que en Vallejo es una exaltación de la cultura soviética y de su acercamiento a las masas, puede leerse desde Benjamin como una verdadera intuición sobre la manera en que la fotografía y el cine cambiaron la percepción humana del arte. Por encima de su entusiasmo político por las obras revolucionarias soviéticas, Vallejo entendió cómo el cine ponía de manifiesto las nuevas formaciones estructurales del arte; esas nuevas formaciones que él mismo buscaba en su poesía. Además, percibe muy lúcidamente el desarrollo del arte en la modernidad, y ambas (modernidad y arte) son constantemente aludidas y relacionadas en sus textos. El cine, por su posibilidad de acercamiento entre el arte y la masa y por su contribución al desarrollo de una nueva sensibilidad artística, resume muchas de las claves

${ }^{29}$ Vallejo, Ensayos y reportajes..., p. 147, nota 1. Vallejo ya había reivindicado el cine mudo en el texto 'Contribución al estudio del cinema', Mundial, 391, 9 diciembre 1927 (I, 511-513). Dice Benjamin: 'Las mismas perturbaciones que, a escala general, propiciaron la búsqueda de modos de salvaguardar la propiedad por la fuerza, llevaron al capital invertido en el cine, ante la amenaza de la crisis, a acelerar la puesta en marcha del cine sonoro'. (Benjamin, p. 22, nota 9). Conviene notar, sin embargo, que el retroceso que produjo el cine hablado se vio atenuado rápidamente por los doblajes e indujo de nuevo a la masa a acudir al cine.

30 'El cinema. Rusia inaugura una nueva era en la pantalla', en Ensayos y reportajes..., p. 155-156, nota 1. 
ideológicas de Vallejo. William Rowe ha estudiado la manera en que el poeta utiliza el cine 'como forma de expresión', para evidenciar la sutil frontera que existe entre sus textos poéticos y sus ensayos periodísticos. No se trata de cómo la teoría estética desarrollada en sus artículos se hace práctica en sus poemas, puesto que existe una estrecha relación entre artículos y poemas no basada en el proceso teórico-práctico, sino en los diferentes estados del proceso creativo. Rowe alude al siguiente fragmento del artículo 'Una gran lucha entre Francia y Estados Unidos', cuando afirma que en él Vallejo nos da 'lo equivalente en la escritura al montaje rápido del cine mudo':

Un señor, vestido de azul y calzado de marrón dos veces, que se abotona cincuenta botones del traje, toma quince vehículos diversos, se quita y se pone el abrigo diez veces, que paga y espera veinte veces la vuelta... ${ }^{31}$

Este texto habla de la velocidad del mundo moderno, como tantos otros artículos, pero Vallejo no echa mano de un discurso 'realista' o lineal, sino que expone una serie de 'saltos rápidos que pasan por delante de los ojos', expresando en momentos puntuales la velocidad de la vida moderna. Paralelamente, Rowe cita el poema que apareció en el segundo número de Favorables París Poema (firmado bajo el seudónimo de Apeles Fenosa, octubre 1926; y luego incluido en Poemas en prosa), titulado 'He aquí que hoy saludo', como una especie de equivalente en verso de ciertas partes de dicho artículo:

He aquí que hoy saludo, me pongo el cuello y vivo, superficial de pasos insondable de plantas.

El poema condensa en el primer verso el 'veloz montaje de la vida moderna': hay una serie de tomas montadas en sucesión: saludar, ponerse el cuello, vivir. ${ }^{32} \mathrm{De}$ nuevo, no se trata de un discurso lineal, sino de la presentación de imágenes sucesivas que se unen mediante saltos en la acción. Es el cine como forma de expresión lo que liga en este caso el texto poético con el ensayo, y pone en práctica ese discurso idóneo, mitad periodístico y mitad cinematográfico, del que hablaba Mariátegui ya en 1925, en su prólogo a La escena contemporánea, antes citado. El cine no se concibe en sus textos como mera reproducción de la realidad en movimiento, sino como una nueva forma de mirar e incluso de ordenar esa realidad;

${ }^{31}$ William Rowe, 'César Vallejo en París: las velocidades de lo moderno', eds. Annina Clerici / Marília Mendes, De márgenes y silencios. Homenaje a Martín Lienhard (Madrid: Iberoamericana Vervuert, 2006), 177-190 (p. 179). La crónica de Vallejo apareció en Mundial, 304, 9 abril 1926 (I, 209-212).

${ }^{32}$ Rowe, p. 180. 
además, se trata un arte de masas y por lo tanto es originalmente moderno. Hay un lenguaje de imágenes, no lingüístico, que dice más de lo que somos capaces de percibir conscientemente.

En definitiva, las crónicas de Vallejo ofrecen múltiples reflexiones sobre los modos de vida del hombre moderno. Estos textos muestran constantemente sus preocupaciones sobre las maneras de mirar un mundo cambiado por las nuevas formas artísticas, así como sus ideas sobre las coordenadas espacio-temporales que impone al hombre moderno la sociedad capitalista avanzada. Son quizá las notas sobre cine las que mejor resumen la relación entre arte y modernidad en el ideario vallejiano. Estas ideas no deberían utilizarse como 'plantilla' para acercarnos a sus poemas, pues resultan mucho más productivas como base para comprender los mecanismos que desarrolla en su poesía, como por ejemplo el boicot a las formas canónicas de pensamiento, a las estructuras del lenguaje o a la percepción sobre coordenadas espacio-temporales homogéneas. Las manifestaciones de lo moderno descritas por Vallejo en sus artículos y crónicas son muy diversas, pero todas ellas tienen que ver con la velocidad, el cambio en la concepción del tiempo y la nueva cultura de masas, marcada por el deporte como espectáculo masivo (la vida deportiva, la vida como match) y sobre todo por el cine. Todas ellas constituyen 'formas de la experiencia masiva', propias de la modernidad, que a través de los textos de Vallejo resumen una época en plena efervescencia cultural y en constante cambio social. 